\title{
A Study of Output Characteristics for the Generation Panel using Unimorph Piezoelectric Element
}

\author{
김용혁 ${ }^{1, a}$ \\ (Yong-Hyuk Kim ${ }^{1, a}$ )
}

\begin{abstract}
The ability for energy harvesting via the piezoelectric effect was studied for a unimorph element such as piezo buzzer. A simple equivalent circuit was proposed to predict the energy generated based on the internal stress. Unimorphs with a metal-cavity were used as a driving device of the generation panel. Both the $\mathrm{AC}$ open voltage and $\mathrm{DC}$ output voltage as a function of pressure period and number of element were measured. For the unimorph generation circuit, DC output voltage varies with pressure period, reaching a maximum value at $470 \mu \mathrm{F}$. The maximum output voltage a according to load resistance was measured at $1 \mathrm{M} \Omega$. Data analysis of the DC output voltage and time constant indicated that number of piezoelectric element of optimum was $60 \sim 80$. It was found that piezoelectric unimorph has the possibility to be used as the driving element of the electric generation
\end{abstract}

Key Words : Unimorph, Energy harvest, Metal-cavity, Piezoelectric element, Generation panel

\section{1.서 론}

화석연료의 연소에 의한 이산화탄소의 배출 문 제로 인해 지구온난화가 가속됨으로서 이에 대한 가장 현실적인 대안으로서 신재생 에너지의 연구 개발이 가속적으로 진행되고 있다. 이와 같은 시대 적 상황에 맞추어 지난 수년간에 걸쳐서 유럽, 미 국 등의 연구소 및 대학에서 압전소재의 기계적 진동에너지를 전기에너지로 변환하여 발전하는 실 행 연구가 [piezoelectric energy harvesting]이란 개념으로 에너지 변환효율이 뛰어난 압전소재의 개발이나 구조변화를 통한 기계-전기변환의 최적 구조에 따른 효율성 증대 등에 초점이 맞추어 연 구가 진행되어왔다[1-9].

예를 들면, 인체의 운동에너지를 추출, 저장하여 군사용 통신장비 등의 전원으로 이용하거나 교량

1. 경원대학교 전기공학과

(경기도 성남시 수정구 복정동 산 65)

a. Corresponding Author : kimyh@kyungwon.ac.kr

접수일자 : 2010. 1. 11

1차 심사 : 2010. 2. 15

심사완료 : 2010. 2. 23
을 주행하는 차량의 진동에너지를 수집하여 조명 용으로 사용하는 발전방식에 관한 연구들을 들 수 있다[10].

이 중에서 Roundy 등은 빔 구조의 압전판 진동 발전장치를 사용하여 진동수에 따른 출력전압과 전력특성을 실험적으로 평가할 수 있는 모델을 제 시하였다[11]. 또한 Sodano et al은 캔틸레버 압전 발전 구조에 대한 수학적 모델을 제시하였고 이어 서 Shen et al은 PZT(piezoelectrics), $\mathrm{MFC}$ (micro fiber composites), PVDF(polyvinylidene fluoride), 소재를 사용한 캔틸레버 구조의 압전발전 장치를 개발하였다[12,13].

이들 연구의 대부분은 바이몰프 구조의 압전체를 기본 소재로 사용한 것으로 압전재료의 특성개선, 진동에너지의 변환효율, 응용분야에 맞춘 전기적 등가회로의 설계 및 분석 등 발전시스템의 효율을 최적화하는 조건에 관한 연구로 이루어져 있다.

유니몰프 압전소자는 바이몰프 압전소자와는 대 조적으로 에너지 추출을 목적으로 개발되었다기 보다는 대부분 압전부저나 액튜에이터와 같이 전 기에너지에 의해서 구동되는 음향효과 또는 기계적 


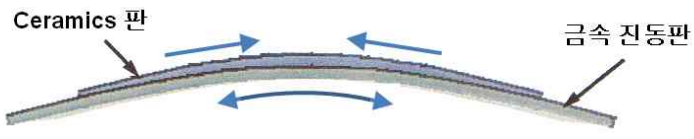

그림 1. 유니몰프의 굴곡모양.

Fig. 1. Bending pattern of unimorph.

위치변위를 목적으로 개발되었다. 압전소자는 기능 면에서 기계에너지와 전기에너지의 상호변환이 가 능하기 때문에 유니몰프 압전체 자체를 에너지 하 베스트용 발전소자에 바로 적용할 수 있음에도 불 구하고 에너지효율이 낮은 관계로 발전용 소자에 응용하고자 하는 시도가 거의 없었다.

유니몰프 압전소자는 금속진동판 위에 원형의 얇은 압전 세라믹 판이 부착된 구조로 되어있기 때문에 구조가 간단하고 취급이 용이하므로 단순 한 제조공정으로 인하여 대량생산이 가능하고 제 조가격이 매우 저렴한 것이 특징이다. 이에 비해서 바이몰프는 박막의 압전판을 샌드위치 형태로 제 작해야 하기 때문에 제조공정이 매우 복잡한 관계 로 고도의 제조공정을 요하는 만큼 제조단가가 매 우 높으므로 고정밀도의 변위를 위한 제어용 액튜 에이터 등에 제한적으로 사용되고 있다.

본 연구에서는 비교적 취급이 용이하고 가격이 매우 저렴한 유니몰프 압전소자를 사용하여 에너 지 변환효율이 뛰어난 발전 판넬의 제작 및 에너 지변환 평가를 통해서 실용 가능한 발전 조건을 제시하고자 한다.

\section{2. 본 론}

\section{1 유니몰프 압전소자의 전기적 등가회로}

유니몰프 압전소자에 외부 압력이 작용하는 경 우 그림 1 과 같은 변형을 나타낸다. 유니몰프의 외 측 세락믹스 부분은 팽창되고 내측의 금속진동판 은 수축되면서 그림과 같은 방향으로 응력이 작용 한다. 압력이 반대방향으로 작용하게 되면 그림의 반대방향으로 응력이 발생한다. 결국 그림 2 와 같 이 상하로 변형을 일으키게 되고 그로 인해 양 전 극 사이에 +- 전하가 교대로 발생하게 된다.

그림 3 과 같이 압전체에 $Z$ 방향으로 외부압력이 작용하는 경우, 압전체 내부에 횡방향(1방향)으로 응력 $\mathrm{T}_{1}$ 이 작용하게 되므로 압전체 내부의 변형에 의해서 3 방향으로 전계 $\mathrm{E}_{3}$ 가 형성되고 $\mathrm{E}_{3}$ 로 인해 전하분포 $\mathrm{D}_{3}$ 가 생성된다[14]. 이 결과로 압전체 표

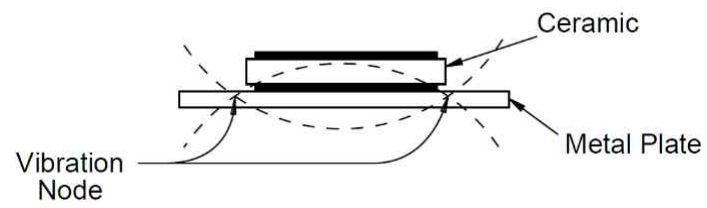

그림 2. 유니몰프의 변위모양.

Fig. 2. Displacement shape of unimorph.
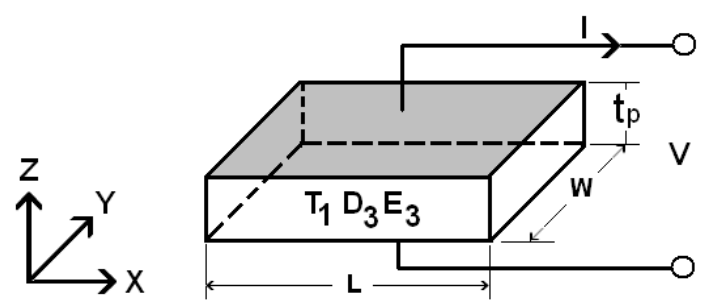

그림 3. 압전체의 전하발생원리.

Fig. 3. Electric charge occurrence principle of piezo element.

면에 전압 $\mathrm{V}$ 가 생성되므로 부하측으로 전류 $\mathrm{I}$ 가 흐르게 된다.

이 조건에 따른 압전방정식은 다음 식으로 나타 낸다.

$$
D_{3}=d_{31} T_{1}+\varepsilon_{33}^{T} E_{3}
$$

즉 압전체 표면에 형성되는 총 전하분포는 내부응 력 $\mathrm{T}_{1}$ 에 의한 전하분포와 전계 $\mathrm{E}_{3}$ 에 의해서 생성 된 전하분포의 합으로 나타난다.

식 (1)을 3 차원 공간에 대한 체적적분은 다음 식으로 나타낸다.

$$
\int\left(\iint D_{3} d A\right) d z=d_{31} \iiint T_{1} d \Psi+\varepsilon_{33}^{T} \iint\left(E_{3} d z\right) d A
$$

전하 $\mathrm{Q}$ 와 전하분포 $\mathrm{D}_{3}$ 의 관계식은 다음과 같다.

$$
Q=-\iint D_{3} d A
$$

전압 $\mathrm{V}$ 와 전계 $\mathrm{E}_{3}$ 의 관계식은 다음 식과 같다.

$$
V=\int E_{3} d z
$$


따라서 전하 $\mathrm{Q}$ 를 다음 식으로 나타낼 수 있다.

$$
-Q=\frac{d_{31}}{t_{p}} \iiint T_{1} d \Psi-\frac{\varepsilon_{33}^{T} A}{t_{p}} V=\frac{d_{31}}{t_{p}} \iiint T_{1} d \Psi-C_{p} V
$$

여기서, $C=\frac{\varepsilon_{33}^{T} A}{t_{p}}$

전류 $i$ 는 다음 식으로 나타낸다.

$$
\begin{aligned}
& i=-\frac{d Q}{d t}=\frac{d_{31}}{t_{p}} \frac{d}{d t}\left(\iiint T_{1} d \Psi\right)-\frac{d}{d t}\left(C_{p} V\right) \\
& =d_{31} A \frac{d}{d t}\left(T_{\text {avg }}\right)-C_{p} \frac{d V}{d t}
\end{aligned}
$$

여기서, 평균응력 $T_{a v g}=\frac{\iiint T_{1} d \Psi}{\Psi}$

평균응력 $T_{a v g}$ 의 harmonic 진동에 의해서 생성된 전압 $V$ 의 페이저 표현은 다음과 같다.

$$
\begin{aligned}
& T_{\text {avg }}=\left|T_{\text {avg }}\right| e^{j \omega t} \\
& V=|V| e^{j \omega t}
\end{aligned}
$$

따라서 식 (6)의 전류 $i$ 의 페이저 식은 다음과 같다.

$$
I_{s}=j \omega d_{31} A T_{a v g}=i+j \omega C_{p} V
$$

이 식으로부터 그림 $4(\mathrm{a})$ 와 같이 전류원 $I_{S}$ 와 정전 용량 $C_{p}$ 의 커패시터가 병렬로 연결된 회로로 등가 화 할 수 있다.

또한 식 (9)를 전압원의 식으로 변환하면 다음 과 같다.

$$
V_{s}=\frac{d_{31} A}{C_{p}} T_{a v g}=\frac{d_{31}}{\varepsilon_{33}^{T}} t T_{a v g}=V+\frac{i}{j \omega C_{p}}
$$

식 (10)은 그림 4(b)와 같이 전압원 $V_{s}$ 와 $C_{p}$ 가 직 렬로 연결된 회로로 등가화 할 수 있다.

따라서 전압원의 등가회로로부터, 압전체 자체 에서 발생되는 에너지는 다음 식으로 된다.

$$
E=\frac{1}{2} C_{p} V_{s}^{2}
$$

결과적으로 외부 응력이 가해졌을 때 압전체로 부터 추출되는 에너지의 양은 압전체 자체의 압전

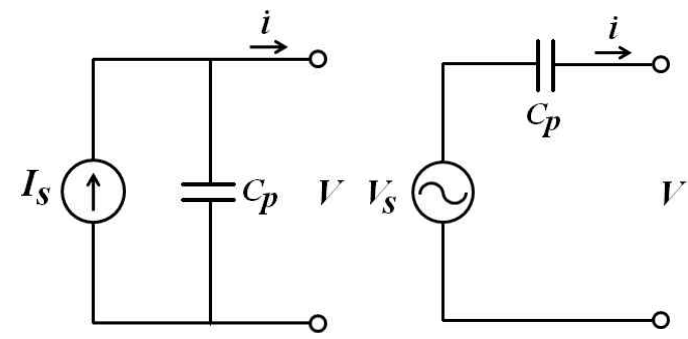

(a)

(b)

그림 4. 압전소자 등가회로 (a) 전류원 등가회로 (b) 전압원 등가회로

Fig. 4. Equivalent circuits of piezo element (a) current source (b) voltage source

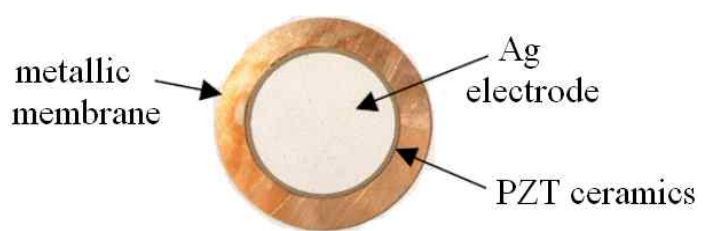

그림 5. 유니몰프 압전소자의 모양.

Fig. 5. Shape of unimorph piezo element.

정수 $d_{31}$, 정전용량 $C_{p}$, 전극면적 $A$ 그리고 외부 작용력에 의해서 압전체 내부에서 발생되는 평균 응력 $T_{a v g}$, 등에 의존됨을 알 수 있다.

\section{2 실험과정}

2.2.1 유니몰프 발전 판넬의 제작

그림 5 에 본 실험에 사용된 유니몰프 압전소자 의 모양을 나타내었다. 원형의 금속 진동판 위에 분극된 $\mathrm{PZT}$ 계 압전세라믹 소결체를 부착하고 그 위에 $\mathrm{Ag}$ 페이스트로 전극 처리한 구조이다. 유니 몰프에 발생된 전하는 $\mathrm{Ag}$ 전극과 금속진동판을 통 해서 외부로 인출된다.

본 실험에서 사용한 유니몰프의 두께 및 크기를 표 1에 나타내었다. 표 2에 유니몰프 압전소재의 전기적 정수를 나타내었다.

유니몰프 압전체를 실장할 동판의 타공구조 개 념도를 그림 6 에 나타내었다. 판넬의 기반이 되는 동판을 직경 $25 \mathrm{~mm}$ 의 타공구조를 갖도록 하여 상, 하로 작용하는 압력에 대해서 유니몰프의 굴곡 반경을 크게 하여 압전효과를 극대화할 수 있는 
표 1. 유니몰프 압전소자의 두께 및 크기.

Table 1. Thickness and diameter of unimorph piezo element.

\begin{tabular}{|l|c|}
\hline Thickness (total) & $0.55 \mathrm{~mm}$ \\
\hline Thickness (ceramic) & $0.1 \mathrm{~mm}$ \\
\hline Diameter (total) & $35 \mathrm{~mm}$ \\
\hline Diameter (ceramic) & $25 \mathrm{~mm}$ \\
\hline Weight (total) & $14.5 \mathrm{~g}$ \\
\hline
\end{tabular}

표 2. 유니몰프 압전소자의 전기적 정수.

Table 2. Electrical constant of unimorph piezo element.

\begin{tabular}{|l|c|}
\hline$\rho\left(\mathrm{kg} / \mathrm{m}^{3}\right)$ & 7800 \\
\hline$d_{33}(\mathrm{pC} / \mathrm{N})$ & 450 \\
\hline$d_{31}(\mathrm{pC} / \mathrm{N})$ & -180 \\
\hline $\mathrm{kt}$ & 0.48 \\
\hline$\varepsilon^{\mathrm{T}}{ }_{33}$ & 1750 \\
\hline $\mathrm{Q}_{\mathrm{m}}$ & 80 \\
\hline
\end{tabular}

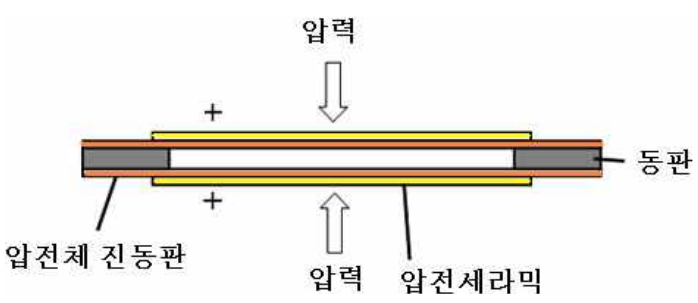

그림 6. 타공구조도.

Fig. 6. Diagram of cavity structure.

구조로 하였다. 그림 7은 발전판넬 구조도로써 타 공구조의 동판에 압전소자를 상, 하로 병렬 배열함 으로써 동일 압력에 대해서 추출되는 전하량이 2 배로 증가하는 구조로 제작하였다. 압력팩은 압력 이 누름판을 통해서 압전소자의 중심에 전달되어 유니몰프에 큰 변위량을 발생시키기 위한 것으로 압전소자의 손상을 방지하기 위하여 탄성고무재질 의 팩을 사용하였다. 누름판은 외부 압력을 압전체 에 골고루 전달시키기 위한 판넬로써 베크라이트 재질의 평판을 사용하였다. 발전판넬은 유니몰프 압전소자 40 개를 각각 동판 상, 하면에 일률적으로 배치한 후, 동테이프를 사용하여 소자 각각에 대해 서 병렬회로로 구성하였다.

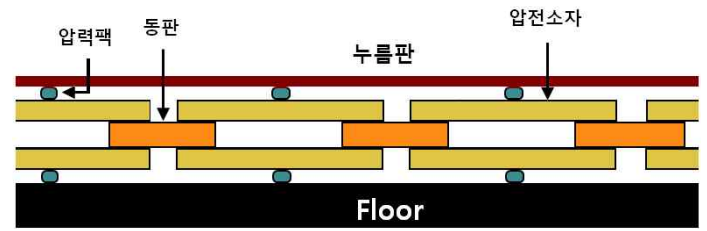

그림 7. 발전판넬 구조도.

Fig. 7. Structure of generation panel.

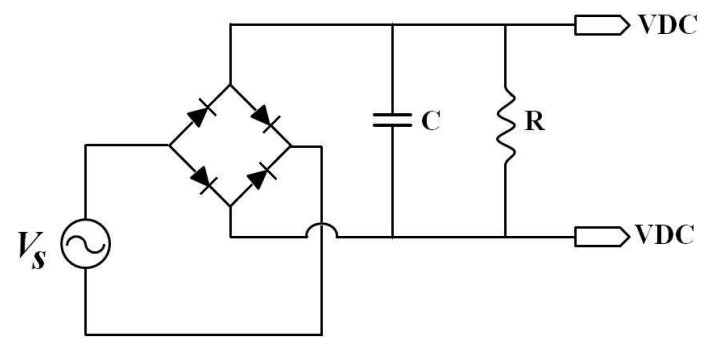

그림 8. 에너지변환 회로.

Fig. 8. Energy converter circuits.

\subsection{2 에너지변환 회로구성}

그림 8에 나타낸 에너지 변환회로의 첫 단계는 유니몰프와 연결된 브리지 정류회로이다. 브리지정 류회로는 그림과 같이 다이오드 4개를 브리지로 연결한 회로로서 다이오드 작용에 의해서 $\mathrm{AC}$ 가 리플파형으로 변환된다. 이때 부하단의 저항 $\mathrm{R}$ 을 삽입하여 입력에 비해서 $\mathrm{AC}$ 사인파의 (-)파형이 제거된 2 배주파수의 전압을 만든 다음 저항 $\mathrm{R}$ 과 병렬로 연결된 평활 커패시터 $\mathrm{C}$ 에 의해서 2 배의 주파수를 갖는 리플파형을 순수 $\mathrm{DC}$ 파형으로 변환 시키게 된다.

\subsection{3 측정}

먼저, 유니몰프 자체에서 발생되는 $\mathrm{AC}$ 전압의 특 성을 조사하기 위하여 유니몰프에 일정한 주기로 압력을 가한 상태에서 유니몰프로부터 발생되는 $\mathrm{AC}$ 전압의 크기(실효값)를 오실로스코프로 측정하 여 컴퓨터의 데이터변환 소프트웨어에 의해서 얻 었다.

다음에, $\mathrm{AC}-\mathrm{DC}$ 에너지 변환회로를 사용하여 정전용량 $470 \mu F, 1000 \mu F, 2000 \mu F$ 조건에서 $\mathrm{DC}$ 출력전압을 조사하였다. 부하저항은 $1 \mathrm{k} \Omega, 10 \mathrm{k} \Omega$, $100 \mathrm{k} \Omega$ 그리고 $1 \mathrm{M} \Omega$ 으로 나누어 부하특성에 따 른 $\mathrm{DC}$ 출력전압을 조사하였다. 그림 9 에 측정시스 템의 사진을 나타내었다. 


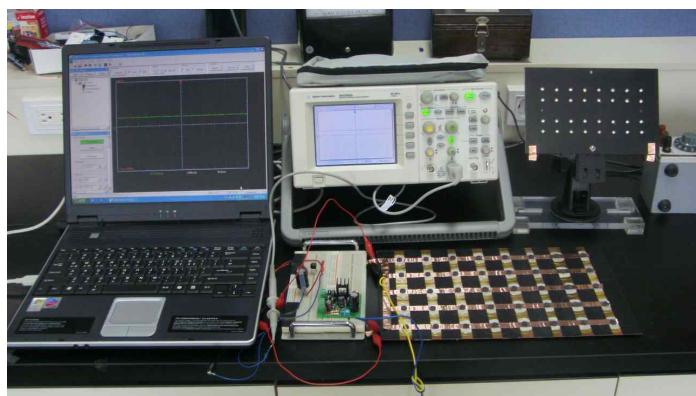

그림 9. 실험 시스템 사진.

Fig. 9. Photograph of experiment system.

\section{3 실험결과 및 고찰}

\subsection{1 가압/이완에 따른 $\mathrm{AC}$ 전압특성}

압전소자는 기계에너지와 전기에너지 사이의 상 호변환이 가능하기 때문에 유니몰프를 발전기능으 로 사용하고자 하는 경우에는 압력에 의한 전하량 발생량의 크기가 매우 중요하다. 앞 이론에서 설명 한 바와 같이 외부의 기계적 에너지는 유니몰프 압전체를 변형시킴으로서 양 전극에 전하를 발생 시키게 된다. 이 전하량의 변화는 전류의 흐름을 유발하게 되므로 양 전극 단에서 $\mathrm{AC}$ 개방전압의 측정이 가능하다.

즉, 외부압력은 압전체 내부의 응력으로 작용하 며 이 응력에 비례하여 전압이 발생되는 $V_{s} \propto T_{a v g}$ 등가이론 식으로 해석할 수 있다.

압전판넬에서 발생되는 순수한 $\mathrm{AC}$ 전압특성을 조사하기 위하여 외부회로를 개방시킨 상태에서 $70 \mathrm{kgf}$ 의 힘으로 $2 \mathrm{sec}$ 간격으로 압력과 이완을 반복했을 때의 개방 $\mathrm{AC}$ 전압(실효치)의 변화를 그 림 10에 나타내었다. 유니몰프가 압력을 받는 순간 에 압전체는 수축이 되고 진동판은 팽창이 되며, 이완시에는 반대로 압전체는 팽창되고 진동판은 수축되는 현상이 일어난다. 이와 같이 팽창과 수축 이 가압 시마다 주기적으로 변화될 때 유니몰프 전극면에는 +전하와 -전하가 주기적으로 생성되기 때문에 그림과 같은 주기성의 교류파형이 발생하게 된다. 압전판넬에 압력을 가한 순간전압이 $\sim+90$ $\mathrm{V}$ 정도로 발생되었으며 이완 시의 순간전압도 가압 시와 동일하게 $-90 \mathrm{~V}$ 전압이 발생되었다.

\subsection{2 압력주기에 따른 AC전압 (Vrms)}

압전판넬에 가해지는 압력주기는 주어진 압력이 가해지는 환경에 따라 달라지기 때문에 출력전압

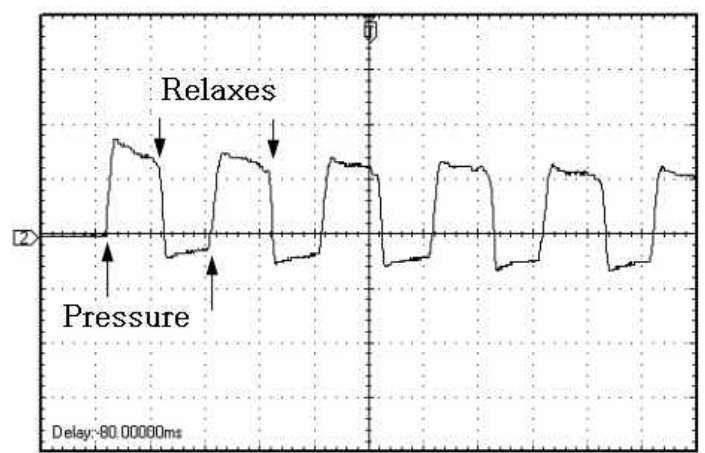

$50 \mathrm{~V} / \mathrm{div} 2.0 \mathrm{~s} / \mathrm{div}$

그림 10. 가압/이완에 따른 $\mathrm{AC}$ 전압특성.

Fig. 10. AC voltage according to pressure and relaxes.

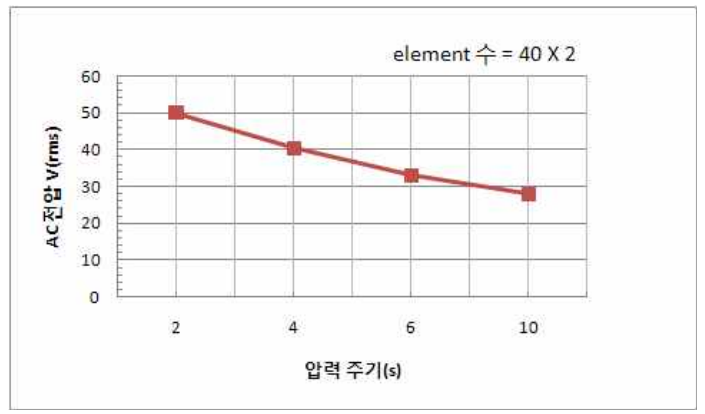

그림 11. 압력주기에 따른 $\mathrm{AC}$ 전압 (Vrms).

Fig. 11. AC voltage according to pressure period.

의 압력주기는 실용면에서 매우 중요하다. 압전판 넬에 인가하는 압력을 2 10 s주기로 변화시켰을 때의 $\mathrm{AC}$ 전압의 실효값 $\mathrm{Vrms}$ 를 그림 11에 나타내 었다. 가압 주기가 증가할수록 $\mathrm{Vrms}$ 는 선형적으로 감소되는 특성을 나타내었다. 압력의 주기가 증가 하게 되면 판넬이 받는 압력주기가 길어지기 때문 에 압전체로부터 방출되는 전하량이 그 만큼 감소 하기 때문인 것으로 볼 수 있다.

실제로 개방 $\mathrm{AC}$ 전압의 피크값과 실효값 $\mathrm{Vrms}$ 사이에 매우 큰 차이를 보이고 있는데 이것은 실 효값이 한 주기 동안의 평균자승에 대한 평방근으 로 계산되기 때문이다.

2.3.3 압전 element 수에 따른 $\mathrm{AC}$ 전압 (Vrms)

그림 12는 element수를 변수로 하여 1 회 가압한 상태에서 20 초 동안 지속시켰을 때의 전압감소 


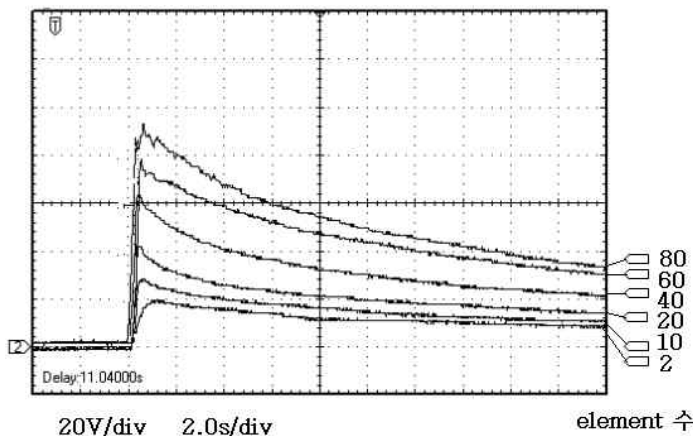

그림 12. 압전 element 수에 따른 $\mathrm{AC}$ 전압파형.

Fig. 12. AC voltage wave according to number of piezo element.

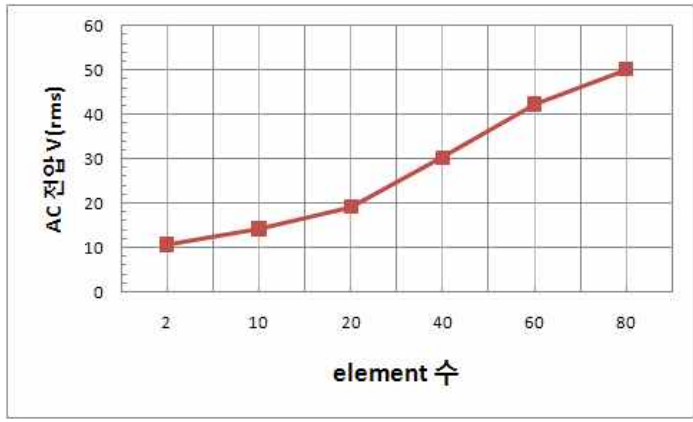

그림 13. 압전 element 수에 따른 $\mathrm{AC}$ 전압 (Vrms).

Fig. 13. AC voltage according to number of piezo element.

현상을 관찰한 것으로 element 수가 증가함에 따 라서 $\mathrm{AC}$ 전압의 피크값이 크게 증가됨을 보이고 있다.

그림 13에 압전 element 수에 따른 $\mathrm{AC}$ 전압 (Vrms)의 변화를 나타내었다. element 수가 증가 할수록 $\mathrm{AC}$ 전압은 크게 증가하였으나 $\mathrm{AC}$ 전압은 element 수에 비례하지 않은 결과로 나타났다.

유니몰프 압전체의 압력은 압력팩을 통해서 가 해지므로 $70 \mathrm{kgf}$ 의 힘이 가해졌을 때 직경 $0.8 \mathrm{~cm}$ 인 압력팩의 면적이 $0.5 \mathrm{~cm}^{2}$ 이므로 상, 하로 구성 된 유니몰프 한 쌍 (element수 $=2)$ 이 받는 압력은 $140 \mathrm{kgf} / \mathrm{cm}^{2}$ 가 되며 이때 발생된 전압은 $10 \mathrm{~V}$ 정 도로 나타났다. 그리고 유니몰프 80쌍이 연결된 발 전 판넬의 경우 상, 하 유니몰프 한 쌍이 받는 압 력은 $1.75 \mathrm{kgf} / \mathrm{cm}^{2}$ 정도로 매우 작다. 이때 전압 은 $50 \mathrm{~V}$ 가 되었다.
이와 같은 결과로 볼 때, $70 \mathrm{kgf}$ 에 있어서의 유 니몰프 한 쌍의 최대전압은 $10 \mathrm{~V}$ 에 이르며 element수가 증가됨에 따라 유니몰프 한 쌍 당에 가압되는 압력이 낮아지기 때문에 element 수가 크게 증가되어도 발생전압은 크게 증가하지 않은 결과로 나타난 것으로 생각된다.

특히 element 수 20 40에서 그 이전보다 $\mathrm{AC}$ 전 압이 급격하게 상승되는 현상을 나타낸 것은 element에서 생성되는 전하량이 그 조건의 압력분 포에서 최대능률을 갖는 조건이 된 것으로 판단된 다. 그리고 element 수 60이상에서 다시 전압의 변 화가 둔화된 것은 element수가 크게 증가됨으로 해서 단위 element에 가해지는 압력이 낮아졌기 때문에 전하를 충분하게 발생시키지 못했기 때문 인 것으로 생각된다.

\subsection{4 압전 element 수에 따른 시정수 $(\tau)$ 특성}

시정수는 압전체에 압력이 가해졌거나 압력이 이완되었을 때 압전체에 생성되거나 소멸되는 전 하량의 시간적 변화속도의 알 수 있는 척도로 사 용된다. 따라서 시정수의 크기는 바로 압전체를 에 너지추출 소자로 사용할 수 있는가, 아닌가를 결정 하는 주요 상수가 된다. 즉 시정수가 크다는 것은 그 만큼 발생된 전하를 오래 동안 유지시킬 수 있 다는 의미이기 때문이다. $\mathrm{AC}$ 전압의 변화는 $v(t)=\frac{q(t)}{C}$ 에 의존되기 때문에 결국 각 소자로부 터 발생되는 전하량 $q(t)$ 의 함수로 작용한다. 그러 므로 가압에 의해서 발생된 전하는 내부저항을 통 한 전압강하로 인해서 출력전압이 감소되는 현상 으로 나타나게 된 것이다.

이와 같은 전압의 감소변화는 압전소자의 합성내 부저항 $R_{t}$ 과 합성정전용량 $C_{t}$ 에 따른 과도현상에 기인된 것으로서 과도변화의 척도인 시정수 $\tau=R_{t} C_{t} \mathrm{sec}$ 를 계산함으로서 전하량의 변화추이 를 알 수 있다. 여기서 저항 $R_{t}$ 은 리드선 저항과 측정 장치의 내부저항 등과 같이 외부회로에 대한 저항의 합으로 나타나게 되므로 소자의 압력변화 에 따른 영향은 크지 않을 것으로 본다.

시정수의 변화특성을 안정된 조건에서 구하기 위하여 1 회 가압 후 압력상태를 일정 시간 유지시 킨 조건에서 $\mathrm{AC}$ 파형의 측정을 통해서 계산하였다 (그림 11).

그림 14에 element 수에 따른 시정수의 변화를 나타내었다. 이 표에서 나타낸 시정수는 $\tau$ 는 최대 값 $\mathrm{V}$ 에 대해서 $0.368 \mathrm{~V}$ 에 이르는 시간으로 정의 


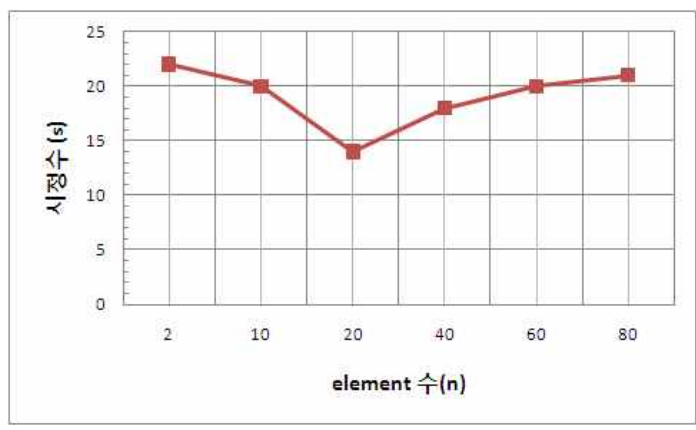

그림 14. Eelement 수에 따른 시정수 $(\tau)$.

Fig. 14. Time constant according to number of piezo element.

해서 나타내었다. Element 수가 증가함에 따라서 시정수가 감소하다가 $n=20$ 에서 $14 \mathrm{~s}$ 로 가장 낮 은 값을 나타낸 후 다시 증가하는 특성을 나타내 었다. 이와 같은 현상은 일정한 압력 하에서, element 수가 적은 경우 $(n=2)$ 정전용량 $C_{t}$ 에 대 한 변화는 없지만 압력이 가해지고 있는 동안 소 자의 기계적 변형에 의한 응력이 계속 유지되고 있기 때문에 전하량의 감소현상이 둔화된 결과로 생각된다. 그리고 element 수 $n=10 \sim 20$ 에서는 정전용량 $C_{t}$ 가 어느 정도 증가하지만 각 소자에 가해지는 압력이 분산됨으로 해서 소자의 변형효 과가 현저하게 감소되기 때문에 발생전하량이 감 소되어 시정수 $\tau$ 가 낮아지는 것으로 판단된다. $n=40 \sim 80$ 에서는 소자 수가 급증하므로 정전용량 $C_{t}$ 가 현저하게 증가하지만 소자 전체를 병렬로 연 결시킨 구조로 되어있기 때문에 발생전하가 큰 폭 으로 증가되기 때문에 시정수 $\tau$ 가 증가된 것으로 생각된다.

이와 같이 각 소자에 가해지는 압력과 소자 수 가 변하는 상황에서는 $R_{t}$ 나 $C_{t}$ 값이 고정되어있지 않기 때문에 일률적으로 $\tau=R_{t} C_{t} \mathrm{sec}$ 를 적용하기 가 곤란한 것으로 생각된다.

결과적으로 같은 압력으로 많은 전하량을 확보 하기 위해서는 가능하면 전압이 높고 시정수가 큰 조건을 선택하는 것이 바람직하므로 element 수에 따른 최적의 조건은 $n=60 \sim 80$ 가 됨을 알 수 있다.

\subsubsection{DC 충전전압}

유니몰프 압전체에 있어서 가압과 이완작용에 의해 압전체 내부의 strain은 그림 $15(\mathrm{a})$ 와 같은

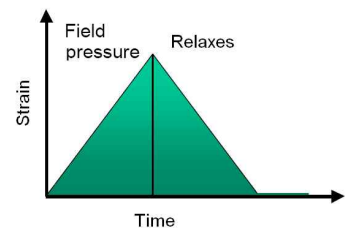

(a)

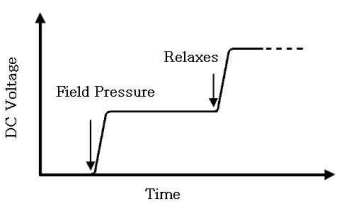

(b)
그림 15. 가압과 이완에 따른 충전과정 (a) Strain 변화 (b) $\mathrm{DC}$ 충전전압.

Fig. 15. Charging diagram according to pressure and relaxes. (a) strain variation (b) DC charging voltage.

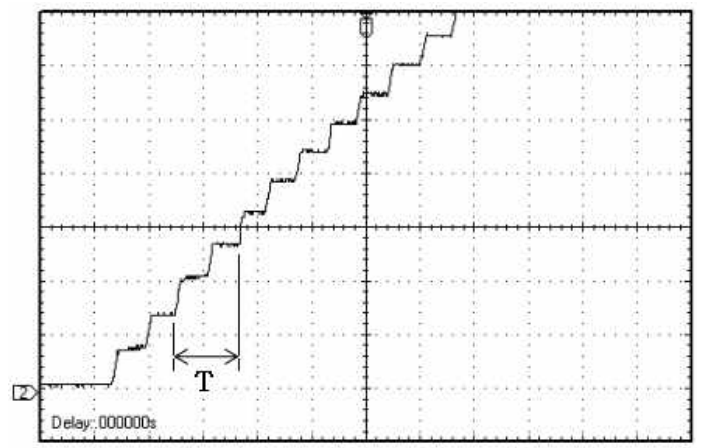

$1.0 \mathrm{~V} / \mathrm{div} 2.0 \mathrm{~s} / \mathrm{div}$

그림 16. 가압주기에 따른 $\mathrm{DC}$ 충전전압.

Fig. 16. DC charging voltage according to pressure period.

변형을 나타낼 것으로 예상된다. 이와 같은 strain 변형에 의해서 내부응력이 작용함으로서 압전체 전극 양면에,+- 전하가 발생된다. 즉 가압/이완 작용에 의해서 발생된 $\mathrm{AC}$ 전압의,+- 파형성분은 브리지 다이오드의 정류작용으로 인해 리플파형의 전압으로 변환되고 다시 콘덴서에 의한 충, 방전 작용으로 인해 그림 $15(\mathrm{~b})$ 와 같이 계단함수의 $\mathrm{DC}$ 전압으로 변환된다.

그림 16 에 element $n=80$ 의 판넬을 $2 \mathrm{~s}$ 주기로 가압했을 때 $C=470 \mu F$ 의 콘덴서 양단에서 측정 한 $\mathrm{DC}$ 충전전압의 변화를 나타내었다. 가압이 반복 될 때마다 대략 $1 \mathrm{~V}$ 의 $\mathrm{DC}$ 전압이 콘덴서에 충전되 는 것으로 나타났다.

가압에 의해서 발생되는 $\mathrm{DC}$ 전압 $V_{D C}$ 는 그림 12 의 $\mathrm{AC}$ 개방전압 실효값 $V_{\mathrm{rms}}$ 와 매우 큰 차이를 


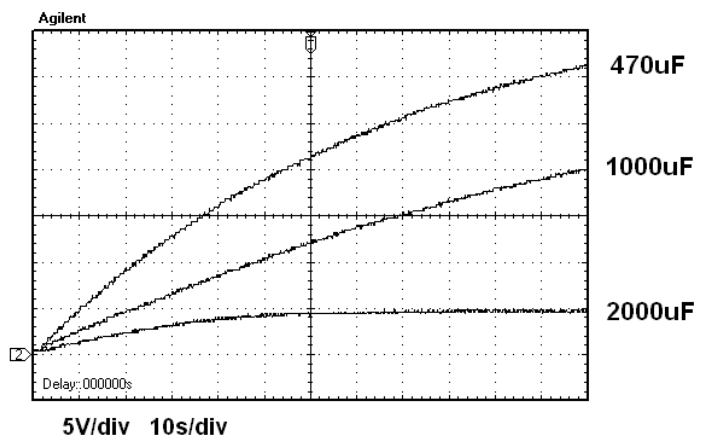

그림 17. 가압 횟수에 따른 콘덴서 충전전압 특성.

Fig. 17. Charging voltage according to number of pressure.

보이고 있음을 알 수 있다. 이와 같은 현상은 $\mathrm{AC}$ 개방전압의 경우 가압되는 순간에 압전체 표면에 대량의 + , -전하가 형성됨으로 해서 그 순간에는 매우 높은 전압이 나타나지만 이때 전하의 이동이 없기 때문에 전류는 거의 흐르지 않는다. 즉 $\mathrm{AC}$ 개 방전압은 순수하게 전하의 생성에 의해서 생긴 전 압인 것이다.

이에 반하여 $\mathrm{DC}$ 전압의 경우는 압전체에서 생성 된 전하가 브리지회로의 다이오드와 콘덴서를 거 치는 전류작용에 의해서 생겨난 전압으로서 에너 지 변환과정에 의해서 전력을 소비하기 때문에 실 제 출력으로 나타나는 전압은 낮아지게 된다.

\subsection{6 에너지저장}

그림 17 에 $2.4 \mathrm{~s}$ 의 가압 주기로서 $120 \mathrm{~s}$ 동안 50 회 반복했을 때 콘덴서양단에 저장된 전압의 변화 를 나타내었다. 이때 사용된 콘덴서 정전용량은 $470 \mu F, 1000 \mu F, 2000 \mu F$ 이다.

콘덴서의 정전용량 $C$ 가 일정한 경우 콘덴서 양 단의 전압 $V$ 는 다음 식으로 된다.

$$
V=\frac{Q}{C}
$$

따라서 콘덴서 양단이 전압 $V$ 는 콘덴서에 유입 되는 전하량 $Q$ 에 비례하여 변하게 된다. 그림에 서, 가압/이완 시간이 증가할수록 전압이 큰 폭으 로 증가하는 특성을 나타낸 것은 매 주기마다 발 생되는 전하량이 콘덴서에 누적되어 저장되기 때 문이다. 그리고 정전용량이 적은 콘덴서 $(470 \mu \mathrm{F})$

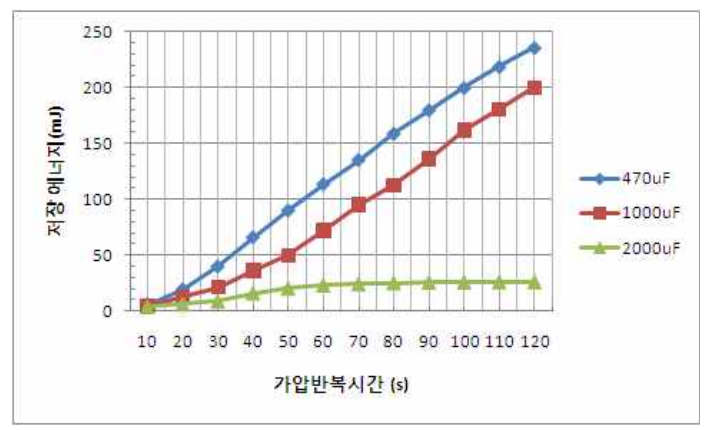

그림 18. 콘덴서 용량에 따른 저장에너지.

Fig. 18. Store energy according to capacitance.

에서 전압이 크게 증가된 것은 식 (12)의 전압과 정전용량의 관계식에 따르기 때문이다.

콘덴서에 전하가 축적되면 전압의 변화로 나타 난다는 것을 앞에서 설명했다. 이때 콘덴서에는 다 음 식으로 표시되는 에너지가 저장된다.

$$
W=\frac{1}{2} C V^{2}
$$

콘덴서에 저장된 에너지 $W$ 는 곧바로 부하회로 에 연결되어 출력에너지로 작용하게 된다. 식 (13) 을 사용하여 그림 17 의 충전전압 $V$ 로부터 구한 저 장에너지 정전용량에 따라서 그림 18 에 나타내었다.

콘덴서의 정전용량 값이 클수록 에너지 저장능 력이 저하되는 것으로 나타났다. 특히 정전용량 $470 \mu \mathrm{F}$ 를 사용한 회로에서 에너지 저장능력이 가 장 뛰어난 것으로 나타났으며 $1000 \mu \mathrm{F}$ 의 회로에 서는 $470 \mu F$ 회로와 거의 비슷한 저장에너지를 나 타냈다. 그리고 $2000 \mu \mathrm{F}$ 의 회로에서는 에너지가 $25 \mathrm{~mJ}$ 정도로 거의 에너지가 저장되지 않는 것으 로 나타났다. 이와 같이 콘덴서의 용량에 따라서 저장에너지가 달라지는 것은 아마도 용량이 큰 콘 덴서일수록 내부저항에 의한 손실이 증가되기 때 문인 것으로 생각된다. 특히 유니몰프와 같이 발생 전하량이 작은 압전체에 있어서 저항손실에 의한 전압강하는 출력특성에 치명적인 요인으로 작용될 수 있기 때문에 최적용량의 콘덴서를 사용하는 것 이 바람직하다.

\subsection{7 부하저항효과}

유니몰프 압전소자로부터 얻은 에너지를 부하 측 으로 최대로 전송하기 위해서는 전원측과 부하측 


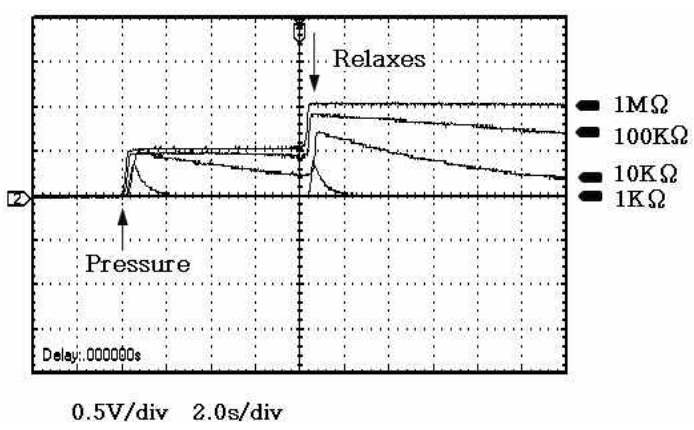

그림 19. 부하저항 효과.

Fig. 19. Effect of load resistance.

사이에 임피던스정합이 이루어져야 한다. 그림 6의 회로에서 부하저항 $R$ 의 크기를 변화시킴으로서 최대 에너지가 전송되는 조건을 찾을 수 있다. 즉 저항 $R$ 에 흐르는 전류가 $R$ 의 크기에 따라서 변하 므로 저항단자에 나타나는 전압이 최대로 될 때 임피던스 정합이 이루어진 것으로 이때의 $R$ 값이 최대에너지를 전송하는 조건이 된다. 그림19에 1 회 가압했을 때 저항값에 따른 부하 단자전압의 변화 를 나타내었다.

이 시스템에서는 부하저항 $1 M \Omega$ 이상에서 최대 전압이 측정되었고 저항값이 낮아질수록 출력전압 은 크게 감소하는 특성을 나타내었다. 따라서 부하 저항이 $1 M \Omega$ 이상이 될 때 임피던스 매칭이 되어 전원측에서 부하측으로 최대전력이 전송된다.

\section{3. 결 론}

본 연구에서는 타공구조의 금속 판넬 위에 유니 몰프 압전소자를 부착시켜 제작한 자가발전 판넬 에 있어서 압력주기의 변화, 유니몰프 소자수의 변 화, 부하저항 등이 발전출력에 미치는 영향에 대해 서 조사하였으며 그에 대한 결론은 다음과 같다.

(1) 주기성 압력에 의해서 발생하는 $\mathrm{AC}$ 개방전 압은 가압시과 이완시에 크기는 같으면서 극성이 다른 전압으로 나타났다.

(2) 판넬에 가해지는 압력 주기가 증가할수록 $\mathrm{AC}$ 개방전압은 감소하는 경향을 나타내었다.

(3) $\mathrm{DC}$ 출력전압과 시정수면에서 가장 이상적인 압전소자 수는 60 80으로 나타났다.

(4) $470 \mu F$ 의 콘덴서를 갖는 에너지저장회로에
서 에너지저장 효율이 가장 높았으며 이때 1 회 가 압시 충전되는 $\mathrm{DC}$ 전압은 약 $1 \mathrm{~V}$ 가 되었다.

(5) 압전소자수 $n=80$ 인 발전판넬에 있어서 이 상적인 부하저항은 $1 M \Omega$ 으로 측정되었다.

(6) 부하저항의 정합이 이루어진 경우, 50 회 가 압작용에 의해서 약 $230 \mathrm{~mJ}$ 이상의 에너지를 발생 시킬 수 있으므로 유니몰프를 이용한 압전발전의 가능성을 확인하였다.

\section{감사의 글}

이 연구는 2009년도 경원대학교 지원 및 2009년 도 중소기업청 산학공동기술개발지원사업에 의한 결과임.

\section{참고 문헌}

[1] T. G. Engel, C. Keawboonchuay, and W. C. Nunnally, "Energy conversion and high power pulse production using miniature piezoelectric compressors", IEEE Transactions on Plasma Science., Vol. 28, No. 5 p. 1338, 2000.

[2] Becker R. Rahman, T. G. Engel, W. C. Nunnally, and J. C. Keawboonchuay, "Research progress on compact kinetic-toelectrical energy converters", Presented in Proceedings of the 12th International Pulsed Power Conference., Vol. 1282, p. 1287, 1999.

[3] W. C. Nunnally, T. G. Engel, and N. B. VanKirk, "Compact kinetic-to-electrical energy conversion", Presented in Digest of Technical Papers 11th IEEE International Pulsed Power Conference., Vol. 1502, p. 1503, 1997.

[4] C. Keawboonchuay, "Maximum power generation in a piezoelectric pulse generator", IEEE Transactions on Plasma Science., Vol. 31, No. 1, p. 123, 2003.

[5] C. Keawboonchuay and T. G. Engel, "Electrical power generation characteristics of piezoelectric generator under quasi-static and dynamic stress conditions", IEEE Transactions on Ultrasonics, Ferroelectrics and Frequency Control., Vol. 50, No. 10, p. 1377, 2003. 
[6] C. Keawboonchuay and T. G. Engel, "Design, modeling and implementation of a 30-kw piezoelectric pulse generator", IEEE Transactions on Plasma Science., Vol. 30, No. 2, p. 679, 2002.

[7] Kennearly C., "2000 a potent new source of electricity", The San Diego Union Tribune, Vol. 17, No. 9, p. 20, 2000.

[8] Goldfarb M. and Jones, L. D., "On the efficiency of electric power generation with piezoelectric ceramic", Journal of Dynamic Systems, Measurement, and Control., Vol. 121, p. 566, 1999.

[9] Umeda M., Nakamura K., and Ueda S., "Analysis of the transformation of mechanical energy to electrical energy using piezoelectric vibrator", Japanese Journal of Applied Physics, Part 1 Regular Papers and Short Notes, Vol. 35, No. 5, Pt. B, p. 3267, 1996.

[10] McGraw-Hill Incorporated, "Darpa explores energy harvesting to power military equipment", Aerospace Daily, p. 363, 1997.

[11] Roundy S., "On the effectiveness of vibrationbased energy harvesting", Journal of Intelligent Material Systems and Structures, Vol. 16, No. 10, p. 809, 2005.

[12] Sodano H. A., Inman D. J., and Park G., "Comparison of piezoelectric energy harvesting devices for recharging batteries", Journal of Intelligent Material Systems and Structures., Vol. 16, No. 10, p. 809, 2005.

[13] Shen D., Ajitsaria J., Choe S. Y., and Kim D. J., "The optimal design and analysis of piezoelectric cantilever beams for power generation devices", Mater. Res. Soc. Symp. Proc., Vol. 3, p. 888, 2006.

[14] H. F. Hofmann, "Energy harvesting using a piezoelectric cymbal transducer in dynamic environment", Japanese Journal of Applied Physics., Vol. 43, No. 9, A, p. 6178, 2004. 